\title{
Relationship between decreased visual acuity and physical activity time in school age children
}

Original article

\author{
Hanna Lee ${ }^{a}$, Jeong-Won Han ${ }^{\text {,** }}$ \\ ${ }^{a}$ Department of Nursing, Gangneung-Wonju National University, Gangwon-do 25457, Korea \\ ${ }^{b}$ College of Nursing Science, Kyung Hee University, Kyunghee-daero, Dongdaemun-gu, Seoul 02453, Korea
}

Received: 3 April 2020; Accepted: 31 August 2020; Published: 20 June 2021

\begin{abstract}
Objective: This study aimed to investigate the physical activity of children with decreased visual acuity, thereby providing basic data for developing strategies to enhance the physical activity of school-age children.

Methods: The participants were 1,194 children and 1,194 parents who participated in the $10^{\text {th }}$ Korean Children Panel Survey. Logistic regression analysis was conducted to examine the status of the physical activity of children with decreased visual acuity according to the accessibility of community facilities.

Results: The mother perceived the accessibility of community facilities as low, children with decreased visual acuity reported 1.20 times shorter over-the-weekend leisure activity time compared with vision-typical children, and they spent 1.41 and 1.33 times shorter on caring for pets and religious activity, respectively.

Conclusions: To increase the physical activity of children with decreased visual acuity, family-oriented interventions should be provided. It is also important to establish a community environment with enhanced accessibility of community facilities by examining the level of accessibility perceived by parents.
\end{abstract}

Keywords: activity $\bullet$ child $\bullet$ community $\bullet$ physical $\bullet$ school

(c) Shanxi Medical Periodical Press

\section{Introduction}

According to 2017 WHO data, around 190 million children under the age of 15 years worldwide are living with decreased visual acuity. ${ }^{1}$ The Korean National Health and Nutrition Survey data also indicate that approximately $48.5 \%$ of children aged between 5 and 11 years reported having myopia, ${ }^{2}$ much higher than the $36.7 \%$ of children between the age of 6 and 15 years in Hong Kong. ${ }^{3}$ Children's eyesight continuously improves from the time of birth, reaching up to $20 / 20$ (1.0) by the time the child reaches the age of 5-6 years; a child who experiences deterioration of eyesight before school age is highly likely to live with decreased visual acuity

How to cite this article: Lee H, Han J-W. Relationship between decreased visual acuity and physical activity time in school age children. Front Nurs. 2021;2:113-120. 
throughout his or her life. ${ }^{4}$ Further, decreased visual acuity can lower children's academic performance and self-esteem by negatively affecting their reading and writing capabilities as well as affect their socialization of children; ${ }^{5}$ as such, decreased visual acuity in children is a critical issue in managing children's health in the growth stage. In particular, school-age children with decreased visual acuity tend to spend less time on physical activity compared with children without decreased visual acuity. ${ }^{6}$ The less time school-age children spend on physical activity, the more likely they are to develop diseases such as obesity, diabetes, cardiovascular diseases, and metabolic syndrome. In this regard, the issue of decreased visual acuity in school-age children needs to be given appropriate attention not only at the individual and family levels but also at the level of society under a thorough and careful management strategy. ${ }^{7}$

Under the ecological model for physical activity of school-age children, their physical activity is influenced by personal, interpersonal, community, and institutional factors. However, studies on school-age children with decreased visual acuity have revealed that physical activity in children with decreased visual acuity has a low level of relationship with personal factors, including gender and personal temperament. ${ }^{8}$ There were differences in the level of physical activity depending on the community where the parents and children are residing; thus, various environmental factors are more important to the level of physical activity of children with decreased visual acuity rather than their personal traits. ${ }^{9}$ Among them, subjective health status perceived by parents is emphasized as a particularly important factor that is related with the physical activity of children. ${ }^{10}$ As school-age children have a high level of interaction with parents, the parents are responsible for increasing the physical activity of their children. ${ }^{11,12}$ Specifically, children with decreased visual acuity are heavily influenced by their parents' values or beliefs, as they are restricted in participating in physical activity owing to decreased visual acuity, and those who do not learn from their parents to participate in physical activity perceive their capacity for physical activity as low, and consequently, they become obsessed with indoor activities, such as indoor games. ${ }^{13}$ Therefore, it is important to identify and discern the traits of parents to confirm the level of physical activity of children with decreased visual acuity.

School-age children spend much time at school, and they should be offered opportunities to participate in physical activities systematically. In Korea, however, most students cannot spend sufficient time on moderate-to-vigorous physical activities at school owing to the curriculum being focused on preparation for college entry exams and the lack of class hours assigned to physical education. ${ }^{8}$ Therefore, the community becomes an important place to offer opportunities for physical activity, as it is located at the middle stage between school and home. ${ }^{14} \mathrm{~A}$ previous study revealed that the level of physical activity in children differs depending on the community where they reside,${ }^{15}$ showing that accessibility of facilities and opportunities offered by the community is important to the physical activity of children. The Centers for Disease Control and Prevention (CDC) also recommends enhancing accessibility of spaces as a strategy to increase physical activity through its "guidelines for community prevention services," citing subjective access and accuracy of perception of physical activity in participants as key determinants of participation in physical activity. ${ }^{16}$ Ultimately, to establish a system for children with decreased visual acuity who are highly dependent on parents, the accessibility of community facilities as perceived by parents needs to be investigated. ${ }^{17}$

Studies on the physical activity of children have mostly focused on children's characteristics, and in particular, little research has been conducted on the physical activity of children with decreased visual acuity owing to restrictions in the sampling of study participants. Moreover, another limitation is that the measurement items of physical activity in children with decreased visual acuity are too simplified, restricting efforts to establish specific strategies to enhance physical activity in this group of children. The present study used the data of a panel survey conducted by the Korea Institute of Child Care and Education (KICCE) under the Ministry of Health and Welfare, and the survey selected representative samples from the master sample of children across the country, including information on family, school, and community environments surrounding children with decreased visual acuity. By using the panel survey data, we identified the factors related to the physical activity of children with decreased visual acuity, and subsequently, we could overcome the limitations of previous studies. Thus, by using the Korea Children Panel Survey data, this study aimed to investigate the relationship between decreased visual acuity and physical activity in children with decreased visual acuity focusing on the subjective health status of their parents and accessibility of community facilities and to provide basic data for establishing plans and strategies for enhancing children's physical activity.

\section{Methods}

\subsection{Research design}

The present study is a cross-sectional descriptive survey research on the relationship between decreased visual acuity and physical activity in school-age children 
focusing on the accessibility of community facilities using the Korea Children Panel Survey data.

\subsection{Participants}

The subjects of this study were children and their parents who participated in the $10^{\text {th }}$ Korea Children Panel Survey. Currently, the data of the Korea Children Panel Survey of up to the $10^{\text {th }}$ survey (2017) are publicly available. The present study used the data of the Korea Children Panel Survey (conducted by the KICCE), a longitudinal survey of newborn babies born in 2008, their mothers, and the community environment. This study used data on the parents aged 19 years or older and their children who participated in the $10^{\text {th }}$ (2017) panel survey. The Korea Children Panel Survey was conducted by the KICCE for all households with newborn babies born between April and July 2008 at a sample medical institution that reported an annual number of births of 500 or more as of 2006 , except for the households that were not included in the sample survey subjects and those that refused to respond to the survey. In cases where the mother could not communicate in the Korean language, where the mother showed very poor postnatal health status, where the newborn baby suffered a serious disease, where the mother suffered a serious disease, where the newborn baby was to be adopted, where the newborn babies were twins or triplets, and where the mother was younger than 18 years old, those households were excluded from the survey. The Korea Children Panel Survey recruited a pilot sample of 2,562 households and then selected 2,150 households with a newborn baby as the final sample. The Korea Children Panel Survey adopted stratified multi-stage sampling. In the first stage, medical institutions where newborn babies are born were selected; in the second stage, households with a newborn baby born at the selected medical institutions were selected as the pilot sample. In the third stage, among the pilot sample households, those households who wanted to participate were selected as the final panel sample. To check the sample validity of the present study, the sample persistency rate presented by the Korea Children Panel Survey team was checked; the results showed that the $10^{\text {th }}$ panel survey $(2017)$ represented $69.0 \%$ of the entire sample. The detailed selection criteria for school-age children adopted in this study were as follows: (1) children at the age of 9 years who participated in all of the panel survey items, (2) children who were living with parents, (3) children who were enrolled in elementary school, excluding those educated through home-schooling, (4) children without any physical and mental disability, (5) children whose parents do not have any disability, and (6) children who were the first-born child of the family. The selection criteria for parents were as follows: those living with the children meeting the selection criteria of this study and who participated in the panel survey (among those without any physical and mental disability). A total of 1,194 children and 1,194 parents were finally selected for the present study, and among them, 263 children wore glasses or used a vision correction device.

\subsection{Measurement}

\subsubsection{Physical activity time}

Physical activity time of children is an item developed by the Korea Children Panel Survey team, referring to the time re-coded by the survey team based on what the children freely drew on a separate sheet of paper regarding the time they spent on corresponding activities while thinking of their routines (excluding special events such as school vacation and field days) during the school day closest to the date of the survey. Trained researchers guided the children to fill out the daily timetable so that no blanks were left in the entire $24 \mathrm{~h}$ of the day; they helped the children to fill out the timetable with the help of their parents or siblings, if necessary. The parents were also told to record the daily activity time of their children during the semester for weekdays and weekends, respectively, and based on the recording of the parents, as well as the timetables made by the children, the physical activity times of children were structured. Detailed items regarding the children's physical activity time included the following: total sleeping time; time for basic life activities (eating meals and snacks, taking a bath, putting on clothes, etc.); time for school life activities (including after-school classes offered within the school); time during which children are educated and cared at institutions other than their school; time during which children do their homework and study on their own; time for e-learning (e.g., internet classes); time for reading books; time for watching videos through the television, computer, or smartphone; time for playing games on a computer, smartphone, or home game console device; time for hobbies, including participating in clubs for entertainment purpose; time for sports and outdoor leisure activities; time for socializing activities with relatives and friends; time spent caring for pets; time for religious activities; time spent helping with house chores; travel time; and others. This study used 15 items, excluding the time spent sleeping at night and other items whose specific details were not available. 


\subsubsection{Accessibility of community facilities}

Accessibility of community facilities was a scale designed by the Korean Children Panel Survey Team and measured by the mothers of the children. It consisted of 13 questions to measure the accessibility of community facilities in the community where the children and their parents lived as of the time of survey. The facilities included playgrounds, parks, promenades, movie theaters, exhibition and experience facilities, performance and play facilities, amusement parks, libraries, indoor sports facilities and playgrounds, outdoor sports facilities, medical institutions, educational institutions, and public welfare facilities. Each question was structured on a five-point scale ( 1 = being very inconvenient, 2 = relatively inconvenient, $3=$ not bad nor good, $4=$ relatively convenient, and $5=$ very convenient). A higher score indicated higher accessibility of community facilities.

\subsubsection{Body mass index (BMI) according to the Ministry of Education Science and Technology (MEST)}

Children's BMI was calculated by the Korean Children Panel Survey team by measuring the height $(\mathrm{cm})$ and weight $(\mathrm{kg})$ of the children. The present study adopted the BMI body somatotype classification method presented by MEST, in which the BMI is calculated with the formula of weight $(\mathrm{kg}) /$ height $\left(\mathrm{m}^{2}\right)$. Further, body somatotype is divided into five stages (underweight, normal weight, overweight, obese, seriously obese) based on the BMI growth chart percentile by gender and age (grade) under the School Health Examination Sampling Survey Operational Manual.

\subsection{Data collection and analysis}

The data of this study were provided through the Korean Children Panel Survey website (http://panel.kicce. re.kr/kor/publication/02.jsp). Researchers submitted a research plan on the utilization of the Korean Children Panel Survey data, obtained approval for the use of the $10^{\text {th }}$ Korean Children Panel Survey data through review, and then downloaded the relevant data. Personal identification codes were deleted from the data used. The collected data were analyzed with the SPSS-WIN Version 20.0 program. For the descriptive statistics of the general characteristics of the research subjects and measurement variables, SPSS descriptive statistics were used. Logistic regression analysis was conducted to examine the relationship between decreased visual acuity and physical activity of school-age children. In addition, this study calculated the odds ratio (OR) and 95\% confidence interval $(95 \% \mathrm{Cl})$ and set the statistical significance level at 0.05 .

\section{Results}

\subsection{General characteristics of participants}

The general characteristics of the parents and children in this study are as presented in Table 1. For the sex of the children, there were 614 boys $(51.4 \%)$ and 580 girls $(48.6 \%)$, and the majority of them, or 382 children $(32.0 \%)$, lived in the Gyeonggi-do and Incheon City areas. The number of children studying at a public school was 1,099 (92.0\%), making up the largest share; 48 children $(4.0 \%)$ reported having experienced transferring between schools. The average household income was KRW 5.388 million. The average age was 42.1 years for the fathers and 39.7 years for the mothers. As for the employment status of the parents, the father was unemployed/not completing education for 90 children $(7.5 \%)$, whereas the mother was unemployed/ not completing education for 572 children (47.9\%). In the majority of the cases, both parents had a four-year university degree.

\subsection{BMI body somatotype classification by MEST for children}

Among the children without decreased visual acuity, $90(9.7 \%)$ were overweight and $46(4.9 \%)$ were obese. Among those wearing glasses or vision assistance devices owing to decreased visual acuity, 90 (7.2\%) were overweight and 46 (8.4\%) were obese (Table 2).

\subsection{Relationship between decreased visual acuity and physical activity of children depending on the accessibility of community facilities}

With the general characteristics of parents and household income was controlled, when the mother perceived accessibility of community facilities as low, children with decreased visual acuity were observed to spend 1.20 times less time on over-the-weekend leisure activities compared with vision-typical children, and they also spent 1.41 times less time on caring for pets and 1.33 times less time on religious activities (Table 3 ).

\section{Discussion}

From the results of the present study, the following implications can be discussed. First, $14.6 \%$ of children without decreased visual acuity were overweight or obese, whereas $15.6 \%$ of those with decreased visual acuity were overweight or obese. Particularly among those who were found to be obese, there was a difference between children with and without decreased visual acuity in the 


\begin{tabular}{|c|c|c|c|c|}
\hline Variables & Category & $n$ & $\%$ & $\mathrm{M} \pm \mathrm{SD}$ \\
\hline \multirow[t]{2}{*}{ Sex } & Male & 614 & 51.4 & \\
\hline & Female & 580 & 48.6 & \\
\hline \multirow[t]{6}{*}{ Region } & Seoul & 132 & 11.1 & \\
\hline & Gyeonggi-do/Incheon & 382 & 32.0 & \\
\hline & $\begin{array}{l}\text { Daejeon/Chungcheongdo/ } \\
\text { Gangwon-do }\end{array}$ & 168 & 14.1 & \\
\hline & Daegu/Gyeongsangbuk-do & 142 & 11.9 & \\
\hline & $\begin{array}{l}\text { Busan/Ulsan/ } \\
\text { Gyeongsangnam-do }\end{array}$ & 223 & 18.7 & \\
\hline & Gwangju/Jeolla-do & 147 & 12.3 & \\
\hline \multirow[t]{4}{*}{ Types of School Establishment } & National School & 69 & 5.8 & \\
\hline & Public school & 1099 & 92.0 & \\
\hline & Private school & 21 & 1.8 & \\
\hline & Alternative school & 5 & 0.4 & \\
\hline \multirow[t]{2}{*}{ School transfer } & No & 1146 & 96.0 & \\
\hline & Yes & 48 & 4.0 & \\
\hline \multirow[t]{3}{*}{ Household income (10,000 won) } & $<500$ & 505 & 42.3 & $538.8 \pm 462.8$ \\
\hline & $500 \geq$ & 571 & 47.8 & \\
\hline & No answer & 118 & 9.9 & \\
\hline \multirow[t]{2}{*}{ Age (Father) } & $<40$ & 299 & 25.0 & $42.1 \pm 3.9$ \\
\hline & $40 \geq$ & 895 & 75.0 & \\
\hline \multirow[t]{2}{*}{ Age (Mother) } & $<40$ & 593 & 49.7 & $39.7 \pm 3.6$ \\
\hline & $40 \geq$ & 601 & 50.3 & \\
\hline \multirow[t]{5}{*}{ Employment status (Father) } & Employed & 1075 & 90.0 & \\
\hline & Academic & 1 & 0.1 & \\
\hline & Work study together & 24 & 2.0 & \\
\hline & Unemployed & 90 & 7.5 & \\
\hline & No answer & 4 & 0.3 & \\
\hline \multirow[t]{4}{*}{ Employment status (Mother) } & Employed & 560 & 46.9 & \\
\hline & Work study together & 43 & 3.6 & \\
\hline & Unemployed & 572 & 47.9 & \\
\hline & No answer & 19 & 1.6 & \\
\hline \multirow[t]{5}{*}{ Education (Father) } & Middle School graduation & 6 & 0.5 & \\
\hline & High school graduation & 317 & 26.5 & \\
\hline & College graduation & 259 & 21.7 & \\
\hline & University graduation & 482 & 40.4 & \\
\hline & Graduate school graduation & 130 & 10.9 & \\
\hline \multirow[t]{5}{*}{ Education (Mother) } & Middle School graduation & 3 & 0.3 & \\
\hline & High school graduation & 324 & 27.1 & \\
\hline & College graduation & 352 & 29.5 & \\
\hline & University graduation & 445 & 37.3 & \\
\hline & Graduate school graduation & 70 & 5.9 & \\
\hline
\end{tabular}

Note: $\mathrm{M}=$ mean, $\mathrm{SD}$ = standard deviation.

Table 1. General characteristics of the participants $(N=1194)$. 


\begin{tabular}{lccccc}
\hline Category & \multicolumn{2}{c}{ Normal $(n=931)$} & & \multicolumn{2}{c}{ Visual impairment $(n=263)$} \\
\cline { 2 - 3 } \cline { 5 - 6 } & $n$ & $\%$ & & $n$ & $\%$ \\
\hline \hline Low weight & 60 & 6.5 & & 15 & 5.7 \\
Normal & 735 & 78.9 & & 207 & 78.7 \\
Overweight & 90 & 9.7 & & 19 & 7.2 \\
Obesity & 46 & 4.9 & & 22 & 8.4 \\
Extreme & 0 & 0.0 & & 0 & 0.0 \\
obesity & & & & & \\
Total & 931 & 100.0 & & 263 & 100.0 \\
\hline
\end{tabular}

Note: MEST $=$ Ministry of Education Science and Technology.

Table 2. BMI classification by children's MEST $(N=1194)$.

obesity rate at $8.4 \%$ and $4.9 \%$, respectively. Such a result is similar to that in a study that analyzed the physical activity of children and youth with decreased visual acuity in Brazil and Italy ${ }^{18}$ : more than half of Brazilian children with decreased visual acuity were classified as being overweight or obese. Thus, decreased visual acuity is related with physical activity, and this, in turn, affects BMI. Medical service providers need to address not only eye health but also physical activity and BMI of children with decreased visual acuity.

Second, children with decreased visual acuity spent less time on physical activities while spending more time on static indoor activities compared with children without decreased visual acuity. Such a result is consistent with the result of a study on children and youth in the United States ${ }^{6}$ : children with decreased visual acuity tend to spend less time on physical activities than their vision-typical peers. Specifically, the issue of a high obesity rate in children with decreased visual acuity as presented in the results of the present study can be considered as leading to the decrease in physical activity time and an increase in static indoor activity time in children with decreased visual acuity. Obesity in school-age children can lead to obesity in adulthood, and thus, it is an important social issue. To address the issue of low physical activity in school-age children with decreased visual acuity, families, schools, and medical professionals need to put together their ideas for establishing appropriate countermeasures. Moreover, as decreased visual acuity in school-age children who are in the stage of developing motor ability can not only restrict their physical activity but also increase the risk of learning disabilities, ${ }^{19}$ families and medical professionals need to intervene proactively from the early stage to address the decreased visual acuity of school-age children.

Third, when parents considered accessibility of community facilities as low, children with decreased visual acuity spent less time on leisure activities, caring for pets, and religious activities over the weekend. This finding is in line with previous study results ${ }^{16,17}$ that perceived and subjective accessibility of community facilities for physical activity and accuracy of perception serve as key determinants of participation in physical exercise. As less time is being provided for moderateto-vigorous physical activities for children at school in $\mathrm{Korea}^{8}$, the community has been transformed into an important place for offering physical activity opportunities to children. ${ }^{14}$ Therefore, the accessibility of community facilities as perceived by the father is directly related with the physical activity level of children. Especially, school-age children have a high level of interaction with their parents, and children with visual impartment often need the help of their parents to participate in physical activities. Therefore, the accessibility of community facilities as perceived by parents seems to be an important factor in increasing the level of activity of both parents and children. In addition, through physical activities, such as weekend leisure activities, caring for pets, and religious activities, children can bond with parents and enjoy emotional pleasure, and specifically, such physical activities enable children to lead an emotionally and psychologically enriched life as well as improve their social participation and social functioning, thereby enhancing the subjective feeling of happiness of children. ${ }^{20}$ Eventually, as can be seen in the results of this study, that children with decreased visual acuity spend less time on weekend leisure activities, caring for pets, and religious activities is not a mere decrease in the level of physical activity but an issue related with the quality of life of children. In this context, it is also required to review the accessibility of community facilities as perceived by parents in establishing a system for enhancing the level of physical activity of school-age children with decreased visual acuity. Moreover, schoolage children mostly tend to depend on the values and judgment of their parents in determining whether to participate in physical activities and the type of activities to participate in; thus, efforts are needed for families, the community, and medical professionals to cooperate and make improvements in the current system to increase the physical activity level of children with decreased visual acuity.

\section{Conclusions}

The present study is a cross-sectional descriptive survey research using the Korean Children Panel Survey data that aimed to examine the relationship between decreased visual acuity and physical activity among school-age children. Unlike previous studies on the physical activity of children that mainly focused on the characteristics of children, the present work is significant in that it considered the characteristics of the community, and it also attempted to overcome limitations in 


\begin{tabular}{|c|c|c|c|c|c|c|}
\hline \multirow[t]{3}{*}{ Variables } & \multicolumn{3}{|c|}{ Total } & \multicolumn{3}{|c|}{ Accessibility of the Community Facility } \\
\hline & \multirow{2}{*}{$\operatorname{Exp}(B)$} & \multicolumn{2}{|c|}{$95 \% \mathrm{Cl}$} & \multirow{2}{*}{$\operatorname{Exp}(B)$} & \multicolumn{2}{|c|}{$95 \% \mathrm{Cl}$} \\
\hline & & Lower & Upper & & Lower & Upper \\
\hline Basic life (weekdays) & 1.00 & 0.78 & 1.30 & 0.87 & 0.59 & 1.28 \\
\hline school life (weekdays) & 0.97 & 0.79 & 1.20 & 0.93 & 0.68 & 1.27 \\
\hline Education care (weekdays) & 0.95 & 0.78 & 1.17 & 0.90 & 0.67 & 1.22 \\
\hline Homework study (weekdays) & 1.15 & 0.83 & 1.58 & 1.27 & 0.79 & 2.04 \\
\hline Communication education (weekdays) & 1.32 & 0.85 & 2.04 & 0.99 & 0.53 & 1.85 \\
\hline Reading (weekdays) & 1.28 & 0.89 & 1.83 & 1.12 & 0.65 & 1.92 \\
\hline TV (weekdays) & 0.82 & 0.63 & 1.06 & 0.76 & 0.52 & 1.12 \\
\hline Game (weekdays) & 1.06 & 0.77 & 1.46 & 0.90 & 0.57 & 1.43 \\
\hline Hobby (weekdays) & 1.24 & 0.87 & 1.76 & 1.28 & 0.75 & 2.19 \\
\hline Leisure (weekdays) & 0.81 & 0.61 & 1.07 & 0.75 & 0.49 & 1.13 \\
\hline Accident (weekdays) & 0.78 & 0.58 & 1.05 & 0.63 & 0.41 & 0.98 \\
\hline Taking care of pets (weekdays) & 1.08 & 0.58 & 2.02 & 0.69 & 0.25 & 1.88 \\
\hline Religious life (weekdays) & 0.46 & 0.20 & 1.02 & 0.32 & 0.09 & 1.10 \\
\hline Household (weekdays) & 1.13 & 0.70 & 1.85 & 1.02 & 0.50 & 2.09 \\
\hline Travel time (weekdays) & 0.97 & 0.66 & 1.43 & 0.87 & 0.50 & 1.53 \\
\hline Basic life (weekend) & 0.96 & 0.80 & 1.16 & 0.77 & 0.58 & 1.02 \\
\hline School life (weekend) & 0.93 & 0.79 & 1.10 & 0.86 & 0.67 & 1.10 \\
\hline Education care (weekend) & 0.91 & 0.74 & 1.11 & 0.83 & 0.61 & 1.12 \\
\hline Homework study (weekend) & 1.01 & 0.81 & 1.27 & 0.83 & 0.59 & 1.16 \\
\hline Communication education (weekend) & 1.19 & 0.85 & 1.66 & 1.18 & 0.72 & 1.93 \\
\hline Reading (weekend) & 1.18 & 0.96 & 1.45 & 0.92 & 0.67 & 1.25 \\
\hline TV (weekend) & 0.93 & 0.81 & 1.06 & 0.90 & 0.74 & 1.08 \\
\hline Game (weekend) & 0.90 & 0.75 & 1.07 & 0.72 & 0.42 & 1.21 \\
\hline Hobby (weekend) & 0.91 & 0.77 & 1.09 & 0.87 & 0.67 & 1.12 \\
\hline Leisure (weekend) & $0.89^{*}$ & 0.59 & 0.91 & $0.83^{*}$ & 0.69 & 0.98 \\
\hline Accident (weekend) & 0.98 & 0.86 & 1.11 & 0.98 & 0.82 & 1.17 \\
\hline Taking care of pets (weekend) & 1.03 & 0.74 & 1.43 & $0.71 *$ & 0.55 & 0.92 \\
\hline Religious life (weekend) & $0.76^{\star}$ & 0.65 & 0.89 & $0.75^{\star}$ & 0.60 & 0.93 \\
\hline Household (weekend) & 1.02 & 0.74 & 1.41 & 0.97 & 0.61 & 1.56 \\
\hline Travel time (weekend) & 0.96 & 0.75 & 1.23 & 0.87 & 0.61 & 1.25 \\
\hline
\end{tabular}

Note: $\mathrm{Cl}=$ confidence interval, reference group: normal child.

${ }^{\star} p<0.005$.

Table 3. Relationship between visual impairment and physical activity according to the accessibility of community facility $(N=1194)$.

the sampling of children with decreased visual acuity by using panel data. However, this study used the data of the panel survey conducted by the KICCE under the Ministry of Health and Welfare, and there are limitations that the variables of parents, children, and the community not presented in the panel survey could not be applied in this study. Future research needs to develop and apply a physical activity promotion program for children under which children with decreased visual acuity, their parents, and the community are interconnected.

\section{Ethical approval}

The $10^{\text {th }}$ Korean Children Panel Survey was conducted after a review by the Institutional Review Board of KICCE. The current work was also conducted after review by the Institutional Review Board of C University (1040271-201903-HR-006).

\section{Conflicts of interest}

All contributing authors declare no conflicts of interest. 


\section{References}

1. World Health Organization (WHO). Blindness and Visual Impairment. Geneva: WHO Media Centre; c2017. http://www.who.int/mediacentre/factsheets/ fs282/en/. Accessed October 11, 2019.

2. Ghaderi $\mathrm{S}$, Hashemi $\mathrm{H}$, Jafarzadehpur $\mathrm{E}$, et al. The prevalence and causes of visual impairment in seven-year-old children. Clin Exp Optom. 2018;101:380-385.

3. Fan DS, Lam DS, Lam RF, et al. Prevalence, incidence, and progression of myopia of school children in Hong Kong. Invest Ophthalmol Vis Sci. 2004;45: 1071-1075.

4. Harper AR, Summers JA. The dynamic sclera: extracellular matrix remodeling in normal ocular growth and myopia development. Exp Eye Res. 2015;133:100-111.

5. Shin HS, Park SC, Park CM. Relationship between accommodative and vergence dysfunctions and academic achievement for primary school children. Ophthalmic Physiol Opt. 2009;29:615-624.

6. Kozub FM, Oh HK. An exploratory study of physical activity levels in children and adolescents with visual impairments. J Am Kinesiother Assoc. 2004;58:1-8.

7. Lee S, Seo H, Jung J. Development and effects of social learning theory based eye-health program for preschoolers. J Korean Acad Nurs. 2018;48:407-418.

8. Lee KC, Cho SM. The Korean national curriculum for physical education: a shift from edge to central subject. Phys Educ Sport Pedagogy. 2014;19:522-532.

9. Haegele JA, Porretta D. Physical activity and schoolage individuals with visual impairments: a literature review. Adapt Phys Activ Q. 2015;32:68-82.

10. Lee DK, Lee Bk. Analysis of parent's effect on the energy expenditure, health consciousness and fitness of boys. Exerc Sci. 2001;10:69-83.
11. Lee Dk. Effects of parent's life style and health consciousness on physical activity and fitness of children. Exerc Sci. 1997;6:115-125.

12. Walker SN, Sechrist KR, Pender NJ. The health promoting lifestyle profile: development and psychometric characteristics. Nurs Res. 1987;36:76-81.

13. Ward S, Fansworth C, Babkes-Stellino M, Perrett J. Parental influences and the attraction to physical activity for youths who are visually impaired at a residential-day school. J Vis Impair Blind. 2011;105:493-498.

14. Perkins K, Columna L, Lieberman L, Bailey J. Parents' perceptions of physical activity for their children with visual impairments. J Vis Impair Blind. 2013;107:131-142.

15. Gronmo SJ, Augestad LB. Physical activity, self-concept, and global self-worth of blind youths in Norway and France. J Vis Impair Blind. 2000;94:522-526.

16. Lackey KJ, Kaczynski AT. Correspondence of perceived vs. objective proximity to parks and their relationship to park-based physical activity. Int J Behav Nutr Phys Act. 2009;6:53-61.

17. Sleddens EFC, Kremers SPJ, Hughes SO, et al. Physical activity parenting: a systematic review of questionnaires and their associations with child activity levels. Obes Rev. 2012;13:1015-1033.

18. Márcia G, Erica G, Attilio C. Physical activity practice, body image and visual impairment: a comparison between Brazilian and Italian children and adolescents. Res Dev Disabil. 2014;35:21-26.

19. Justin A. Physical activity and school-age individuals with visual impairments: a literature review. Adapt Phys Activ Q. 2015;32:68-82.

20. Kim S, Kong M. An in-depth study on supporting cultural and recreational activities for school-age children with severe disabilities. Kor J Clin Psychol. 2016;23:657-671. 